\title{
A construção do direito à saúde e do SUS no cenário neoliberal e a contribuição do Serviço Social
}

The construction of healthcare right and SUS on neoliberal context and the Social Service's contribution

\author{
GABRIELA CRISTINA BRAGA BISCO (1.1 \\ FERNANDA DE OLIVEIRA SARRETA (1.1 \\ ${ }^{1}$ Universidade Estadual Paulista, Franca, SP, Brasil.
}

RESUMO - O presente artigo apresenta os resultados parciais obtidos a partir de pesquisa bibliográfica, realizada no mestrado em Serviço Social da Universidade Estadual Paulista, com apoio da Capes. O objetivo geral do estudo é analisar a política de saúde e a contribuição do trabalho da/o assistente social para a efetivação do direito à saúde no cenário contemporâneo. Como resultado, constata-se que o direito à saúde e o Sistema Único de Saúde (SUS) são conquistas da classe trabalhadora por melhores condições de vida e atendimento às suas necessidades; e, o Serviço Social, é uma profissão que contribui de maneira efetiva para o acesso da população às ações e aos serviços de saúde. No entanto, com o avanço do neoliberalismo, do ataque e do retrocesso nos direitos sociais, o trabalho da/o assistente no SUS é tensionado com os desafios expressivos, as demandas complexas e o aprofundamento das expressões da questão social na saúde. É um cenário que exige uma atuação crítica e propositiva, na direção do projeto ético-político profissional e da reforma sanitária para a construção de estratégias e respostas coletivas na defesa da universalidade desse direito.

Palavras-chave: Política de saúde. Serviço Social. Direito à saúde.

ABSTRACT - This article presents partial results collected from a bibliographic research made on the Social Service's master degree college, with the support by CAPES. The objective of this study is to analyze healthcare policy and the social assistant's work for effecting healthcare right in the contemporary setting. As a result, it is verified that healthcare right and SUS are conquests from the working class for better life conditions and meeting its basic needs; and the Social Service is a profession that effectively contributes for people's access to healthcare actions and services. However, with the advancement of neoliberalism, attack, and regression on social rights, the assistant's work on SUS is tensioned with expressive challenges, complex demands and deepening of expressions on the healthcare's social question. It is a scenario that demands critic and propositional action, aiming towards the ethic-political professional project and the sanitation reform, constructing strategies and collective answers defending this right's universality.

Keywords: Health Policy. Social Service. Right to health. 


\section{Introdução}

Serviço Social é uma profissão que apresenta um Projeto Ético-Político Profissional coerente ao Projeto da Reforma Sanitária, na defesa do Sistema Único de Saúde (SUS) constitucional (BRASIL, 1988), como política do Estado brasileiro e uma conquista da classe trabalhadora. No cenário contemporâneo, no entanto, a saúde reconhecida como direito de todos e dever do Estado, vem sofrendo os rebatimentos da orientação neoliberal e de seu projeto privatista, exigindo da sociedade e da categoria profissional a defesa intransigente dos direitos sociais e dos princípios consagrados constitucionalmente.

Portanto, é fundamental que o Serviço Social desenvolva estudos e análises para aprofundar reflexões e debates sobre essa realidade contraditória. A compreensão da complexidade da política de saúde e da saúde como direito universal, exige uma análise crítica à luz da totalidade para o desvendamento dessa realidade, para que seja capaz de romper com a aparência e o reducionismo, no processo de apreensão do real. A partir dessa intenção, o estudo que deu base a esse artigo tem como referência o materialismo histórico dialético, que (MINAYO, 2009, p. 24) "[...] considera a historicidade dos processos sociais e dos conceitos, as condições socioeconômicas de produção dos fenômenos e as contradições sociais". Nesse sentido, permite uma compreensão da saúde e dos problemas que se materializam em doenças, sofrimentos, filas e outras situações apresentadas cotidianamente, como expressões articuladas.

Para conhecer com profundidade essa realidade, a área da saúde, o trabalho realizado, suas particularidades, as conquistas e retrocessos, é preciso um esforço para ultrapassar a imediaticidade dos fenômenos apresentados à população, que culpabilizam, individualizam, e retiram a responsabilidade do Estado e seus determinantes estruturais. Apenas assim, é possível compreender as múltiplas determinações que compõem essa realidade social, orienta Paulo Netto (2011).

Para lamamoto (2000) exige da/o assistente social,

[...] uma competência crítica capaz de decifrar a gênese dos processos sociais, suas desigualdades e as estratégias de ação para enfrentá-las. Supõe competência teórica e fidelidade ao movimento da realidade; competência técnica e ético-política que subordine o 'como fazer' ou 'o que fazer' e, este ao 'dever ser', sem perder de vista seu enraizamento no processo social (IAMAMOTO, 2000, p. 80).

A pesquisa partiu do pressuposto de que o Serviço Social na área da saúde é uma categoria profissional que tem um papel importante no desenvolvimento de ações que ampliem o acesso da população aos direitos assegurados no SUS, uma vez que têm contribuído efetivamente para ampliar o acesso às ações de saúde, conforme resultados do estudo realizado anteriormente por Bisco (2015). Frente aos limites impostos pelo cenário de regressão dos direitos e de desmonte do SUS constitucional, de privatização, focalização e terceirização da saúde, o trabalho da/o assistente social na saúde deve reafirmar a direção do Projeto Ético-Político Profissional e do Projeto da Reforma Sanitária.

A pesquisa teve como objetivo geral analisar a política de saúde e a contribuição do trabalho da/o assistente social para a efetivação do direito à saúde no cenário contemporâneo, na Santa Casa de Franca/ SP; e, como específicos, refletir sobre o direito social à saúde tendo como referência as atribuições do assistente social na saúde e evidenciar as principais demandas do Serviço Social e como a categoria apresenta respostas a essas demandas.

O artigo apresenta os resultados parciais obtidos a partir de pesquisa bibliográfica, realizada no Programa de Pós-Graduação em Serviço Social, nível mestrado, da Faculdade de Ciências Humanas e Sociais - UNESP de Franca/SP. A pesquisa contou com bolsa da Coordenação de Aperfeiçoamento de Pessoal de Nível Superior (CAPES) - Demanda Social, oportunizando a dedicação exclusiva à pesquisa. $O$ projeto de pesquisa não necessitou de submissão na Plataforma Brasil, uma vez que não envolveu coleta de dados em campo com seres humanos, conforme orientação repassada pelo Comitê de Ética em Pesquisa (CEP) da Faculdade. 


\section{Contextualização da política de saúde no Brasil}

A compreensão da atual condição e estrutura da política de saúde no Brasil exige o resgate histórico de como a política social surgiu no país, e em qual contexto sócio-histórico o Estado intervém na questão social, por meio de políticas públicas para amenizar as desigualdades sociais. A expressão "amenizar" é utilizada para mostrar que diante do atual modelo de sociedade, excludente e contraditória, características próprias do capitalismo no cenário contemporâneo, não é possível acabar radicalmente com as injustiças sociais nem essa seria a intenção do capitalismo, uma vez que ele necessita produzir desigualdade para ampliar seus lucros.

As políticas de proteção social surgem para amenizar as expressões da questão social, no início do século XX. A partir do seu reconhecimento por parte do Estado, foi preciso intervir de alguma maneira na sociedade, como forma de amenizar as situações de desigualdade social, de controle da classe trabalhadora frente à sua organização e reivindicações. A questão social compreendida como:

[...] as expressões do processo de formação e desenvolvimento da classe operária e de seu ingresso no cenário político da sociedade, exigindo seu reconhecimento como classe por parte do empresariado e do Estado. É a manifestação, no cotidiano da vida social, da contradição entre o proletariado e a burguesia, a qual passa a exigir outros tipos de intervenção mais além da caridade e repressão (IAMAMOTO; CARVALHO, 1982, p. 77).

Portanto, as expressões da questão social manifestam o conflito entre as classes sociais em determinada sociedade, e se agudizam na medida em que as desigualdades se expandem.

No final do século XIX e início do século XX, vários países do mundo vivenciaram um aumento de legislações e medidas de proteção social que buscavam, de alguma maneira, amenizar os conflitos e as reivindicações da classe trabalhadora, assegurando alguns direitos como forma de manutenção da ordem social.

Na análise de Behring (2006), as políticas de proteção social são produtos do próprio sistema capitalista e do seu modo de produzir e reproduzir-se. Dessa forma, tais políticas surgem tanto como interesse do capital para manutenção da ordem vigente, como também a partir das lutas e reivindicações da classe trabalhadora. A autora ressalta que é importante uma análise crítica da política social, sem reducionismos, uma vez que ela não pode ser vista apenas como uma conquista dos trabalhadores a partir da sua pressão sobre o Estado na garantia de direitos sociais. Dessa forma, é preciso fazer essa análise de modo a contemplar a totalidade, buscando a apreensão das múltiplas determinações e complexidades que compõem a política social.

Nesse sentido, é fundamental entender o papel do Estado na sociedade capitalista para compreender o contexto de como os direitos sociais e as políticas de proteção social surgiram. A definição do papel do Estado passou por diferentes interpretações ao longo do tempo, e passou a ter uma discussão mais ampla a partir do século XVI, com a decadência da sociedade feudal.

Desde Maquiavel, tem-se a busca de uma abordagem racional do exercício do poder político por meio do Estado. Naquele momento, este era visto como uma espécie de mediador civilizador (Carnoy, 1988), ao que caberia o controle das paixões, ou seja, do desejo insaciável de vantagens materiais, próprias aos homens em estado de natureza (BEHRING, 2006, p. 15, grifo do autor).

Outros estudiosos possuem diferentes definições do papel do Estado na sociedade. Behring (2006) analisa que para Hobbes, o Estado deveria ser uma opção racional, como forma de frear as paixões, o seu "estado de natureza". Para John Locke deveria haver um pacto entre os sujeitos coletivos de uma comunidade, com a finalidade de proteger a vida, a liberdade e a propriedade, surgindo assim a associação entre o poder e a propriedade. Na visão de Jean-Jacques Rousseau, o correto seria a firmação de um contrato social, pois a sociedade foi corrompida pela propriedade e, dessa forma, o poder do Estado deveria estar nas mãos do povo, na cidadania por meio da vontade geral e seria, então, um Estado de Direito. 
A partir do século XVIII, com o avanço do capitalismo e das ideias liberais, novas definições sobre o papel do Estado surgiram, evidenciando a preocupação central com o mercado, e não com o seu papel de mediador das relações sociais e desigualdades. Adam Smith, considerado um dos maiores pensadores do liberalismo econômico, defendia que o Estado deveria realizar uma intervenção mínima na sociedade, pois os indivíduos são conduzidos por uma "mão invisível" (mercado), e dessa forma o Estado deveria fornecer as bases legais para uma maximização do mercado. A partir de suas ideias, o capitalismo se consolida com base no ideário de uma sociedade fundada no mérito de cada indivíduo potencializar suas capacidades consideradas supostamente como naturais, explica Behring (2006).

Tais argumentos elaborados pelos pensadores liberais entraram em crise ao longo da segunda metade do século XIX e início do século XX. Alguns fatores foram determinantes para essa crise, e o principal deles foi o envolvimento da classe trabalhadora e operária nas questões políticas, reivindicando direitos até então não assegurados. Além disso, a concentração de renda e a monopolização do capital, aliada a grande crise mundial de 1929, desencadearam uma crise estrutural do capital.

Mészáros (2000), que aprofunda seus estudos sobre a crise estrutural do capital, explica que isso não significa que o capital está decaindo, e sim que está buscando outras formas para se reinventar. E, é nessas crises, que surge a barbarização da vida social, com a degradação dos homens e da natureza. A busca por melhores condições de vida e pela garantia de direitos, mobilizou a classe operária do mundo todo que passou a exigir respostas por parte do Estado, principalmente, com o agravamento das expressões da questão social.

No Brasil, o capitalismo e a formação do Estado se desenvolveram de forma diferente do resto do mundo, porém, mantendo as bases de desenvolvimento do sistema capitalista. Dessa forma, as políticas de proteção social surgiram em um contexto diferente.

O Estado brasileiro nasceu sob o signo de forte ambiguidade entre um liberalismo formal como fundamento e patrimonialismo como prática no sentido da garantia dos privilégios das classes dominantes. O desenvolvimento da política social entre nós, como se verá, acompanha aquelas friç̧ões e dissonâncias e a dinâmica própria da conformação do Estado (BEHRING; BOSCHETTI, 2011, p. 75).

O capitalismo se desenvolveu no País carregando marcas antigas de desigualdades sociais profundas. Apesar das desigualdades sociais serem marcantes no País desde o seu período de colonização e escravidão, somente no século XX a questão social e as suas expressões passaram a ser reconhecidas, exigindo uma intervenção do Estado.

No entanto, é necessário compreender que a intervenção estatal no Brasil na área da saúde, ocorreu tardiamente, na década de 1930 do século XX, segundo Bravo (2006). A autora esclarece que, anteriormente à intervenção do Estado nesta área, o Brasil passou pela Reforma Carlos Chagas, que ocorreu em 1923. A reforma buscava uma expansão do atendimento à saúde uma vez que, nesse período, tornaram-se evidentes as questões de higiene e saúde do trabalhador, o que possibilitou a criação das Caixas de Aposentadorias e Pensões (Caps), através da Lei Elói Chaves. As Caps eram financiadas pela União e pelas empresas e empregados, e previam os benefícios de "assistência médica-curativa e fornecimento de medicamentos; aposentadoria por tempo de serviço, velhice e invalidez, pensão para os dependentes e auxílio-funeral" (BRAVO, 2006, p. 90).

A política de saúde no Brasil a partir da década de 1930 foi formulada em caráter nacional e dividida em dois subsetores: o da saúde pública e o da medicina previdenciária, sendo o primeiro com focalização na criação de condições sanitárias para a população urbana, e restritamente para a população do campo; e o segundo, que consegue sobressair o subsetor de saúde pública a partir da década de 1960 (BRAVO, 2006).

A década de 1960 foi marcada pela intensa repressão de direitos durante a ditadura militar brasileira e, os problemas estruturais que já existiam no País, e as mais variadas expressões da questão social, se agudizaram e tornaram-se mais complexas. Na área da saúde surgiu o modelo de privilegiamento do setor privado, sendo que esse modelo possuía como características: 
Extensão da cobertura previdenciária de forma a abranger a quase totalidade da população urbana, incluindo, após 1973, os trabalhadores rurais, empregadas domésticas e trabalhadores autônomos; Ênfase na prática médica curativa, individual, assistencialista e especializada, e articulação do Estado com os interesses do capital internacional, via indústrias farmacêuticas e de equipamento hospitalar; Criação de um complexo médico-industrial responsável pelas elevadas taxas de acumulação de capital das grandes empresas monopolistas internacionais na área de produção de medicamentos e de equipamentos médicos; Interferência estatal na previdência, desenvolvendo um padrão de organização da prática médica orientada para a lucratividade do setor da saúde, propiciando a capitalização da medicina e privilegiando produtor privado desses serviços; Organização da prática médica em moldes compatíveis com a expansão do capitalismo no Brasil, com a diferenciação do atendimento em relação à clientela e das finalidades que esta prática cumpre em cada uma das formas de organização da atenção médica (BRAVO, 2006, p. 94).

O setor privado, as empresas e os grandes monopólios de medicamentos e tecnologias, passaram a integrar de alguma forma a política de saúde no Brasil. Além disso, o que houve na época foi a expansão da prática médica baseada somente nos problemas individuais e não na saúde coletiva da população, com tratamentos diferenciados, privilegiando as classes com melhores condições de renda que podiam arcar com os custos do atendimento médico particular, em detrimento daqueles que precisavam recorrer às ações de caridade e filantropia.

Foi apenas nas décadas de 1970 e 1980 que o Brasil vivenciou um processo de democratização e uma efervescência política e social, que culminou em uma nova Constituição e buscou a expansão de direitos sociais. Nesse período, novos sujeitos participam das discussões sobre política e sobre as reais condições e direitos da classe trabalhadora e da população. Na área da saúde, esse momento de efervescência política mobilizou a população e as entidades representativas na luta pela saúde pública e de qualidade, sendo reconhecido como Movimento da Reforma Sanitária.

As principais propostas debatidas por esses sujeitos coletivos foram a universalização do acesso; a concepção de saúde como direito social e dever do Estado; a reestruturação do setor através da estratégia do Sistema Unificado de Saúde, visando profundo reordenamento setorial com um novo olhar sobre a saúde individual e coletiva; a descentralização do processo decisório para as esferas estadual e municipal, o financiamento efetivo e a democratização do poder local através de novos mecanismos de gestão - os Conselhos de Saúde (BRAVO, 2006, p. 96).

A luta pela saúde pública universal teve como um dos principais marcos a 8a Conferência Nacional de Saúde (BRASIL, 1986), realizada em 1986, em Brasília, e foi o marco da representatividade desses sujeitos coletivos, que incluíam trabalhadores da saúde, sindicatos, associações de moradores e movimentos sociais, que tinham como objetivo questionar e debater propostas com a intenção de estabelecer as responsabilidades do Estado em relação à saúde, questionando o direcionamento que estava sendo dado à saúde até então. De acordo com Finkelman (2002), os princípios da Reforma Sanitária brasileira eram:

1) A melhoria das condições de saúde da população; 2) o reconhecimento da saúde como direito social universal; 3 ) a responsabilidade estatal na provisão das condições de acesso a esse direito; 4) a reorientação do modelo de atenção, sob a égide dos princípios da integralidade da atenção e da equidade; 5) a reorganização do sistema com a descentralização da responsabilidade pela provisão de ações e serviços (FINKELMAN, 2002, p. 242).

O movimento defendia a melhoria das condições de vida da população, e uma nova formulação da política de saúde no Brasil, que deveria ter como princípios fundamentais a universalidade do acesso, a integralidade da atenção e a participação da comunidade, entre outros, e a responsabilidade do Estado para 
assegurá-la. A preocupação central dos sujeitos que discutiam a Reforma Sanitária era a responsabilidade do Estado na área da saúde e nas políticas sociais, na análise de Bravo (2006, p. 101) "pautando-se na concepção de Estado democrático de direito".

A promulgação da Constituição de 1988 representou "a promessa de afirmação e extensão dos direitos sociais em nosso país frente à grave crise e às demandas de enfrentamento dos enormes índices de desigualdade social" (BRAVO, 2006, p. 96). Assim, fica estabelecida a criação de um Sistema Único de Saúde (SUS), com a integração de forma hierarquizada de todos os serviços públicos de saúde do País, devendo ser descentralizado para facilitar o acesso às ações de saúde.

As conquistas com a criação do SUS são expressivas, no entanto, o mercado privado consegue garantir a sua participação na saúde de forma complementar aos serviços, preferencialmente com entidades filantrópicas.

\begin{abstract}
Percebe-se que a construção da ideia que afirma a necessidade do setor privado para o atendimento das necessidades humanas encontra terreno favorável quando uma gama muito grande de necessidades básicas, historicamente, não tem lugar garantido na esfera das opções e decisões macroeconômicas governamentais. Dessa maneira, visualiza-se uma aceitação, um consenso e um consentimento ideologicamente forjados, em meio à falta de opções, da proposta privatizante que responda com recursos públicos às necessidades do público usuário (RAVAGNANI, 2013, p. 18).
\end{abstract}

Portanto, apesar do direito à saúde ser garantido constitucionalmente, a participação complementar do setor privado surge como forma de opção em meio à precarização dos serviços de saúde, com uma falsa ideologia de que o mercado privado possui melhor qualidade.

\title{
2 A construção do direito social à saúde
}

Os direitos sociais conquistados historicamente foram pauta das reivindicações de movimentos sociais e da classe trabalhadora. Portanto, "a criação dos direitos sociais no Brasil resulta da luta de classes e expressa a correlação de forças predominantes" (BEHRING; BOSCHETTI, 2011, p. 79). De acordo com Marshall (1967), os direitos sociais a partir do século XX surgiram como forma de assegurar um mínimo de bem-estar social.

A instituição dos direitos sociais logrou modificar, em parte, a desigualdade social. No final do século XIX havia se iniciado um novo período, com o primeiro grande avanço dos direitos sociais e suas mudanças significativas no princípio igualitário da cidadania (SIMÕES, 2008, p. 60).

Portanto, fica evidente que a tensão entre capital e trabalho, e o poder político da classe trabalhadora, foi um importante marco para a luta pelos direitos sociais.

As políticas de proteção social, nas quais se incluem a saúde, a previdência e a assistência social, são consideradas produto histórico das lutas do trabalho, na medida em que respondem pelo atendimento de necessidades inspiradas em princípios e valores socializados pelos trabalhadores e reconhecidos pelo Estado e pelo patronato. Quaisquer que sejam seus objetos específicos de intervenção, saúde, previdência ou assistência social, o escopo da seguridade depende tanto do nível de socialização da política conquistado pelas classes trabalhadoras, como das estratégias do capital na incorporação das necessidades do trabalho (MOTA, 2004 apud MOTA 2006, p. 40).

O capital sempre buscou adequar a Seguridade Social aos seus interesses, uma vez que ela é tanto uma necessidade dos trabalhadores, como também alvo de disputas e negociações da burguesia (MOTA, 
2006). As políticas de Seguridade Social se ampliaram ao longo dos anos e em geral, foram implementadas por meio de:

[...] ações assistenciais para aqueles impossibilitados de prover o seu sustento por meio do trabalho, para cobertura de riscos do trabalho, nos casos de doenças, acidentes, invalidez e desemprego temporário e para manutenção da renda do trabalho, seja por velhice, morte suspensão definitiva ou temporária da atividade laborativa (MOTA, 2004a apud MOTA 2006, p. 41, grifos do autor).

No Brasil, a Seguridade Social é composta por um tripé e compreende o direito à saúde, à assistência social e à previdência social, conforme Artigo 1 ㅇ da Lei no 8.212, de 24 de julho de 1991, que dispõe sobre a organização da Seguridade Social (BRASIL, 1991). O Conselho Federal de Serviço Social (CFESS) elaborou a Carta de Maceió, reafirmando a defesa da Seguridade Social pública, onde reafirma a "concepção de seguridade, entendida como um padrão de proteção social de qualidade, com cobertura universal para as situações de risco, vulnerabilidade ou danos dos cidadãos brasileiros" (CFESS, [2000]).

Ao longo dos anos, os direitos civis, políticos e sociais, foram sendo garantidos por meio das Constituições promulgadas no País, sendo que cada Constituição apresenta em seus artigos os princípios e contextos demandados de cada época histórica em que foram criadas. A Constituição Federal de 1988 (BRASIL, [1988]), ou cidadã, como é reconhecida, é considerada a que mais avançou em termos da garantia de direitos, principalmente os direitos sociais, como saúde, educação, proteção à criança e adolescente, idosos, previdência social e seguridade social.

A garantia de um direito, por meio da Constituição Federal não significa que ele está sendo efetivado. As transformações societárias contemporâneas têm afetado o mundo do trabalho como um todo, além da vida da classe trabalhadora, no que diz respeito aos direitos historicamente conquistados a partir de lutas e reivindicações da própria população.

Essa mudança ocorre com o avanço do ideário neoliberal, que estabelece um novo modelo de acumulação de capital, com uma renovação das ideias liberais. Esse novo modelo de acumulação "inclui (por definição) a informalidade do trabalho, o desemprego, o subemprego, a desproteção trabalhista e, consequentemente uma 'nova' pobreza'" (SOARES, 2000, p. 12). Portanto, com o projeto neoliberal surge a flexibilização, desregulamentação e privatização de serviços que deveriam ser garantidos pelo Estado, ou seja, uma nova configuração mundial que altera os modos de produção e, também, o papel do Estado. Esse passa a transferir sua responsabilidade para a sociedade civil, o terceiro setor e as entidades filantrópicas, impactando nas políticas sociais, em especial, no campo da Seguridade Social e do trabalho. Além disso, as políticas sociais, que deveriam ser universais, passam a ter caráter focalizado e seletivo.

O direito universal à saúde foi conquistado pela sociedade brasileira após lutas e resistências contra o ideário neoliberal, no início da década de 1970, e se fortaleceu na década de 1980, após a segunda grande crise financeira associada ao baixo crescimento econômico de vários países do mundo. Entretanto, no cenário atual, o que se constata é o desmonte dos direitos da classe trabalhadora.

Desde 2013 a conjuntura do país apresenta um quadro de grandes mobilizações sociais frente aos ataques do capital, por meio do patronato e do Estado, com precarização das condições de vida dos trabalhadores imposta pela terceirização, desemprego estrutural crescente, desregulamentação das relações de trabalho e cortes orçamentários em políticas sociais que reduzem direitos sociais e trabalhistas arduamente conquistados (ABRAMIDES, 2017, p. 367).

Diante do retrocesso histórico aos ataques na vida da classe trabalhadora e aos direitos fundamentais como educação e saúde, o Serviço Social é uma profissão fundamental para a luta pelos direitos sociais da classe trabalhadora. O Projeto Ético-Político Profissional organiza-se na defesa da universalidade das políticas sociais e da responsabilidade do Estado na sua garantia; assim, nos espaços de trabalho profissional, a categoria atua na edificação de uma sociedade justa e igualitária, atuando para que as/os usuárias/os reconheçam os seus direitos e passem a reivindicá-los. 
Conforme explicitado na Carta de Maceió, a defesa da concepção ampliada de saúde é a referência para o Serviço Social, como uma conquista da população brasileira. O conceito de saúde ao longo dos anos passou por diversas transformações até alcançar a concepção ampliada e garantida na Constituição Federal (BRASIL, 1988). Anteriormente, a saúde estava somente relacionada à ausência de doenças, sem um conceito que reconhecesse as diversas dimensões que a ela se relacionam.

As diferentes definições estão tanto no conceito de saúde como na própria etimologia, da palavra saúde. Filho (2011), parte do pressuposto de que o conceito de saúde:

Diz respeito a uma realidade rica, múltipla e complexa, referenciada por meio de conceitos, apreensível empiricamente, analisável metodologicamente e perceptível por seus efeitos sobre as condições de vida dos sujeitos. Essa linha e problematização e as hipóteses dela decorrentes se desdobram num debate atual e oportuno a propósito das bases filosóficas, científicas e práticas do conhecimento sobre fatos e fenômenos, ideias e processos relativos à saúde (FILHO, 2011, p. 15).

Dessa forma, a análise do conceito de saúde deve ser crítica, capaz de apreender as múltiplas determinações que compõem esse conceito, buscando uma definição ampliada, sem reducionismos. Filho (2011) destaca, ainda, que a palavra "saúde" possui diferentes significados em diferentes línguas, porém, tanto no latim, no português, no francês e no italiano, a palavra possui significados semelhantes relacionados ao todo, total, totalidade e inteiro. Isso significa que a saúde não pode ser vista a partir de aspectos isolados, sem conexões e sem nexos com outros conceitos, o que inclui as dimensões físicas, sociais, intelectuais e espirituais.

$\mathrm{Na}$ história da humanidade, diferentes pensadores e filósofos antigos estiveram em busca de uma definição do conceito de saúde e de doença, e já problematizavam essa questão. Aristóteles (1985) em um de seus livros destaca a saúde e a doença como conceitos opostos: "[...] saúde e doença são contrários, mas nem $m$ nem outro é verdadeiro nem falso [...] o bom é ao mesmo tempo bom e não mau; a primeira destas qualidades pertence-lhe por essência, e a segunda, por acidente, pois só por acidente o bom é mau" (ARISTÓTELES, 1985, p. 164).

Pode-se considerar, portanto, que saúde e doença possuem significados distintos, e que a saúde não se resume apenas na ausência de doenças, pois ela engloba definições mais amplas. De acordo com a definição da Organização Mundial de Saúde (OMS, 1946), a saúde é um estado de completo bem-estar físico, mental e social, e não consiste apenas na ausência de doença ou de enfermidades. A partir dessa definição, a saúde dos indivíduos está relacionada também ao ambiente em que eles vivem e aos fatores econômicos, sociais, culturais, de higiene entre outros, esclarece Sarreta (2010).

$\mathrm{Na}$ Constituição Federal brasileira de 1988, a saúde tem seu marco legal e passa a ser garantida como um direito fundamental a todos os cidadãos, sem distinção de classe social, cor, raça, etnia e gênero. A saúde passa a ser considerada como: [...] direito de todos e dever do Estado, garantido mediante políticas sociais e econômicas que visem à redução do risco de doença e de outros agravos e ao acesso universal e igualitário às ações e serviços para sua promoção, proteção e recuperação (BRASIL, 1988, p. 118).

Desse modo, o conceito de saúde é ampliado e definido não somente como a ausência de doenças, considerando a redução do risco de adoecimento e o agravamento de doenças, especialmente, o desenvolvimento de atividades de prevenção e promoção associadas à assistência em saúde. Além disso, a Constituição prevê que a saúde é um direito de todos e um dever do Estado, abrangendo fatores condicionantes e determinantes para a saúde da população (BRASIL, 1988).

A transformação no conceito ampliado de saúde foi histórica e marcante para a população, pois só foi possível a partir de um movimento social que contou com a reivindicação de trabalhadores de saúde, sindicatos, associações, e a própria população que lutava por melhores condições de vida e por direitos universais, por ocasião do Movimento pela Reforma Sanitária, nas décadas de 1970 e 1980.

Bravo (2006) reflete que a Constituição de 1988 foi uma importante conquista para a população brasileira, na direção da garantia de direitos, sendo introduzida a ideia da extensão dos direitos sociais, buscando corrigir as desigualdades historicamente acumuladas nos séculos anteriores. Dessa maneira, 
assegura os direitos universais de acesso à saúde, à previdência e à assistência social, ou seja, o tripé da Seguridade Social.

A regulamentação do SUS estabelece a concepção ampliada de saúde, com a Lei Orgânica de Saúde de no 8080/90, alterada pela Lei no 12.864 de 2013, em seu Art. 3:

Os níveis de saúde expressam a organização social e econômica do País, tendo a saúde como determinantes e condicionantes, entre outros, a alimentação, a moradia, o saneamento básico, o meio ambiente, o trabalho, a renda, a educação, a atividade física, o transporte, o lazer e o acesso aos bens e serviços essenciais.

Parágrafo único. Dizem respeito também à saúde as ações que, por força do disposto no artigo anterior, se destinam a garantir às pessoas e à coletividade condições de bem-estar físico, mental e social (BRASIL, [1990]).

Nesta direção, Nogueira e Mioto (2006) destacam que o acesso universal e igualitário da população aos serviços de saúde representa a possibilidade de ruptura com a desigualdade social no Brasil; antes da Constituição de 1988 o acesso à saúde estava restrito aos trabalhadores que contribuíam com a previdência social, e aos outros cidadãos, ou seja, à maioria da população, restava os serviços de caridade e filantropia, como as Santas Casas de Misericórdia.

Conforme já apontado, anteriormente, a efetivação do SUS enfrenta desde os anos de 1990 as orientações do projeto neoliberal para a saúde, onde a direção privatista orienta a focalização e a seletividade, neste sentido, apresenta o mercado privado como alternativa viável para a saúde. A assistência à saúde é livre à iniciativa privada, indicando as condições para participar do SUS, disposto no Artigo no 199 da Constituição, o que possibilitou a consolidação dos planos de saúde no País, uma vez que a população ao não ter este direito assegurado, acaba buscando alternativas que possam atender às suas necessidades, como os planos privados.

Segundo Bravo (2006), nessa lógica neoliberal, cabe ao Estado apenas assegurar o mínimo para quem não pode arcar com os custos da saúde privada, e o mercado oferece serviços para aqueles que podem pagar. Este projeto distancia a responsabilidade do Estado em assegurar a saúde para todos os cidadãos com igualdade e equidade.

O projeto saúde, articulado ao mercado, ou a reatualização do modelo médico assistencial privatista, está pautado na Política de Ajuste, que tem como principais tendências a contenção dos gastos com recionalização da oferta e a descentralização com isenção de responsabilidade do poder central (BRAVO, 2006, p. 101).

Para Costa (1997) o projeto privatista tem como principais características a focalização dos serviços para atender à população mais vulnerável, com um pacote básico de serviços de saúde, ampliando a privatização, o estímulo ao seguro privado, a descentralização dos serviços ao nível local e a eliminação de fonte com relação ao financiamento. Complementando essa análise, Bravo e Matos (2006) esclarecem que as políticas sociais continuam fragmentadas e focalizadas, e na área da saúde, mesmo após o avanço constitucional, o Projeto de Reforma Sanitária e o projeto privatista continuam em disputa.

O SUS proposto na Constituição de 1988, foi regulamentado pela Lei no 8080 de 1990 (BRASIL, 1990) que dispõe sobre todas as condições necessárias para a promoção e a recuperação da saúde dos indivíduos, regulamentando ainda todo o funcionamento e a organização dos serviços de saúde no país. Os objetivos e as atribuições do SUS são:

Art. 5ㅇ $[\ldots]$

I - a identificação e divulgação dos fatores condicionantes e determinantes da saúde; $[\ldots]$

III - a assistência às pessoas por intermédio de ações de promoção, proteção e recuperação da saúde, com a realização integrada das ações assistenciais e das atividades preventivas (BRASIL, [1990]). 
Reafirma-se que o SUS deve ser organizado a partir das seguintes diretrizes: "I - descentralização, com direção única em casa esfera do governo; II - atendimento integral, com prioridade para as atividades preventivas, sem prejuízo dos serviços assistenciais; III - participação da comunidade" (BRASIL, 1988, p. 119).

Essas diretrizes representam conquistas expressivas do ponto de vista da responsabilidade na gestão da saúde, ou seja, do atendimento integral que considera não apenas a recuperação da saúde de indivíduos, grupos e comunidades, do mesmo modo, da prevenção e da participação da comunidade nas decisões sobre a gestão e o planejamento da política de saúde, destacando o papel dos Conselhos de Saúde. De acordo com Raichelis (2006), os Conselhos são os espaços democráticos de participação social nas decisões sobre a saúde do País, fortalecem:

[...] a ideia de que os espaços de representação social na organização e gestão das políticas sociais devem ser alargados para permitir a participação de novos e diversificados sujeitos sociais, principalmente os tradicionalmente excluídos do acesso às decisões do poder político (RAICHELIS, 2006, p. 78).

Ainda, segundo a autora, "são espaços que estão sendo construídos pela ação coletiva de inúmeros sujeitos sociais" (RAICHELIS, 2006, p. 84). E ainda, "podem provocar mudanças substantivas na relação Estado-sociedade [...] e contribuir com a construção/consolidação de uma cultura política contra-hegemônica, por meio da prática da socialização da política e da distribuição de poder" (RAICHELIS, 2006, p. 84).

Entretanto, contrariando os objetivos da Reforma Sanitária e de todos os avanços consideráveis do SUS, o projeto neoliberal ganha força na década de 1990, reafirmando o projeto privatista e a focalização das políticas sociais nos mais pobres. Dessa maneira, "[...] a afirmação da hegemonia neoliberal no Brasil, tem sido responsável pela redução dos direitos sociais e trabalhistas, desemprego estrutural, precarização do trabalho, desmonte da previdência pública, sucateamento da saúde e educação" (BRAVO, 2006, p. 100).

As consequências da orientação neoliberal recaem nas políticas sociais e na política de saúde para o desmonte do SUS, sendo que os recursos governamentais que deveriam ser repassados para o setor público, são cada vez mais desviados para o setor privado. Filho (1982) analisa que, como o recurso governamental para a saúde não é capaz de oferecer assistência à toda a população brasileira, a população necessita buscar a saúde suplementar através dos planos de convênio. Esse processo está sendo cada vez mais fortalecido no País, o que demonstra o afastamento do Estado de suas responsabilidades e a presença do setor privado na política pública de saúde, além dos crescentes processos de terceirização.

No SUS, como nos bairros periféricos, há descuido com ambiência, com a eficiência da gestão pública e, o mais grave, com as pessoas que usam e trabalham no sistema. O SUS vem se transformando, gradualmente, em mais um espaço dominado pela racionalidade da velha e tradicional promiscuidade da política brasileira. Em síntese, o SUS vem conformando uma ética, uma estética e um padrão de funcionamento em correspondência com o modo de vida da maioria; em muitos aspectos e situações, confirmando um padrão de descaso e de desrespeito à dignidade humana (CAMPOS, 2018, p. 5).

A análise de Campos (2018) demonstra que cada vez mais o SUS está sendo enfraquecido tanto pela própria política, que é cada vez mais seletiva e focalizada, quanto pelos próprios gestores e trabalhadores da saúde, que parecem se conformar com a atual situação do Brasil e da política nacional de saúde.

A luta por uma política de saúde universal e dos princípios e diretrizes do SUS, é uma luta coletiva. É preciso também, lutar contra as desigualdades sociais e econômicas, buscando uma sociedade justa e igualitária, por meio de políticas públicas que fortaleçam os direitos da população. As reflexões de Campos (2018) apontam a defesa do SUS como um compromisso da sociedade brasileira, através da luta pelo fortalecimento do Projeto da Reforma Sanitária: 
[...] a defesa do SUS, da democracia e dos direitos sociais, nesse momento em particular, depende da sociedade civil mais do que do Estado e dos políticos profissionais. Depende da revitalização do movimento sanitário e de sua articulação com amplos setores da sociedade - movimentos de luta por direitos, como o das mulheres, dos idosos, das populações indígenas e negra, dos portadores de patologias, das várias crenças religiosas que participam também da vida social, dos sindicatos, enfim, temos que verbalizar um projeto inclusivo de sociedade e, especificamente, de direito à saúde (CAMPOS, 2018, p. 5).

É preciso retomar o processo histórico de reivindicações e lutas para que o SUS seja efetivamente universal, público, gratuito e com capacidade de atender à toda a população com qualidade, equidade e respeito.

\section{Considerações finais}

O Serviço Social é uma profissão comprometida com as lutas coletivas pelo direito universal à saúde, diante do desmonte do SUS, como política do estado brasileiro. O trabalho da/o assistente social na saúde é marcado pelo compromisso ético e político, e pelo debate permanente da categoria, para buscar respostas e alternativas qualificadas às expressões da questão social na saúde.

Diante da complexidade das demandas e dos atendimentos cotidianos, é preciso dar visibilidade no trabalho desenvolvido, nas estratégias construídas, demonstrando a importância da atuação profissional na política de saúde nos municípios do País. Ainda, é importante problematizar tais demandas com a população para o reconhecimento da saúde como direito, buscando fortalecer a participação popular nas decisões sobre o que envolve a própria vida.

O trabalho da/o assistente social por natureza é um trabalho interventivo, atua diretamente na realidade cotidiana da população, buscando conhecer e se aprofundar nessa realidade para orientações que irão refletir na vida desses sujeitos. O trabalho profissional necessita de um permanente subsídio teórico e metodológico, para mediar a intervenção e contribuir para que o trabalho seja crítico, reflexivo, propositivo e transformador, reconhecendo os sujeitos como protagonistas de suas histórias.

Os princípios que orientam o Projeto Ético-Político Profissional do Serviço Social têm estreita relação com os princípios do SUS e do Projeto da Reforma Sanitária, portanto, devem orientar a atuação da/o assistente social na saúde (CFESS, 2010). É nessa direção que os desafios devem ser enfrentados, coletivamente.

Os resultados da pesquisa evidenciam o desmonte do SUS, a complexidade das demandas na saúde e o agravamento das expressões da questão social na vida dos sujeitos. Portanto, é necessário investir em pesquisas para desvendar essa realidade, suas contradições e interesses, para que a categoria possa contribuir com o fortalecimento do direito à saúde.

Na saúde a/o assistente social é desafiada/o profissionalmente, uma vez que por ser um profissional assalariado, depende das condições objetivas das instituições que atuam para o desenvolvimento de seu trabalho. Além disso, a matéria de trabalho do assistente social são as próprias políticas públicas, que asseguram direitos para população. Essa atuação, depende também do desenvolvimento e da efetivação dessas políticas.

Na área da saúde é evidente, portanto, que os desafios fazem parte do cotidiano profissional, mas é preciso refletir como a/o assistente social tem enfrentado esses desafios? O fortalecimento da categoria profissional é uma possibilidade de enfrentamento dos limites cotidianos. Esse fortalecimento reflete positivamente no trabalho profissional, permitindo que a população também se fortaleça e passe a reivindicar os seus direitos (BISCO, 2015). A construção de espaços participativos e democráticos dentro das instituições aproxima os usuários, movimentos sociais, trabalhadores e outras profissões que compartilham os mesmos princípios e valores do Serviço Social, com a finalidade de somar forças para resgatar o SUS universal e com qualidade para toda a população. 


\section{Referências}

SANJUÁN, C. R. Prólogo. La nueva lectura de Marx. In: HEINRICH, Michael. Crítica de la economía política: Una introducción a El Capital de Marx. Madrid: Escolar y Mayo Editores, 2008. https://doi.org/10.5377/realidad.v0i121.3331

ABRAMIDES, M. B. C. Lutas sociais e desafios da classe trabalhadora: reafirmar o projeto profissional do serviço social brasileiro. Serviço Social e Sociedade. São Paulo, n. 129. 2017. https://doi.org/10.1590/0101-6628.113

ARISTÓTELES. Ética a Nômaco. São Paulo: Abril Cultural, 1985.

BEHRING, E. R. Política de saúde no Brasil. Serviço Social e Saúde: formação e trabalho profissional. São Paulo: Cortez, 2006.

BEHRING, E. R; BOSCHETTI, Ivanete. Política Social: fundamentos e história. 9. ed. São Paulo: Cortez, 2011.

BISCO. G. C. B. Serviço social na saúde: limites e desafios para efetivação de direitos dos usuários na Santa Casa de Franca/SP. Franca. São Paulo. 2015. https://doi.org/10.20396/sss.v6i1.8634947

BRASIL. [Constituição (1988)]. Constituição da República Federativa do Brasil. Promulgada em 5 de outubro de 1988. Brasília, DF: Senado Federal, 1988. Disponível em: https://www2.senado.leg.br/bdsf/ bitstream/handle/id/ 518231/CF88_ Livro_EC91_2016.pdf. Acesso em: 06 fev. 2019. https://doi.org/10.11606/d.2.2010.tde-13122010-160747

BRASIL. Ministério da Saúde. Relatório Final da 8a Conferência Nacional de Saúde. Brasília: Ministério da Saúde, 1986. https://doi.org/10.1590/s0103-11042012000400007

BRASIL. Ministério da Saúde. Lei orgânica da saúde de no 8.080 de 19 de setembro de 1990. Brasília: Ministério da Saúde, 1990. Disponível em: http://www.planalto.gov.br/ccivil_03/leis//8080.htm. Acesso em: 23 out. 2018. https://doi. org/10.11606/d.22.2007.tde-13112007-162850

BRASIL. Ministério da Saúde. Lei orgânica da Seguridade Social de no 8.212 de 24 de julho de 1991. Brasília: Ministério da Saúde, 1991. https://doi.org/10.5327/z1679443520190289

BRAVO, M. I. S. Política de saúde no Brasil: Serviço social e saúde: formação e trabalho profissional. São Paulo: Cortez, 2006.

BRAVO, M. I. S.; MATOS, M. C. de. Projeto ético-político do serviço social e sua relação com a reforma sanitária: elementos para o debate. Serviço social e saúde: formação e trabalho profissional. São Paulo: Cortez, 2006. https://doi.org/10.1590/ s0101-66282011000400013

CAMPOS, G. W. S. A defesa do SUS depende do avanço da reforma sanitária. Interface - comunicação, saúde, educação, v. 22, n. 65, 2018. https://doi.org/10.1590/1807-57622017.0772

CFESS. Parâmetros para atuação de assistentes sociais na política de saúde. Série: Série Trabalho e Projeto Profissional nas Políticas Sociais. Brasília: CFESS, 2010. https://doi.org/10.22422/temporalis.2018v18n35p265-288

CFESS. Carta de Maceió, Seguridade Social pública: é possível!. In: ENCONTRO NACIONAL CFESS/CRESS, 26., Maceió, 2000. Disponível em: http://www.cfess.org.br/arquivos/encontronacional_cartas_maceio.pdf. Acesso em: 26 nov. 2018. https://doi. org/10.17012/entac2014.599

COSTA, N. R. O Banco Mundial e a Política Social nos Anos 90: Agenda para reforma do setor saúde no Brasil. Política de saúde e inovação institucional: uma agenda para os anos 90. Rio de Janeiro: ENSP, 1997. https://doi.org/10.1590/s001152581996000300007

FILHO. N. de A. O QUE É SAÚDE? Rio de Janeiro: Editora Fiocruz, 2011.

FILHO, G. C. A “Questão Social” no Brasil: crítica do discurso político. Rio de Janeiro: Civilização Brasileira, 1982.

FINKELMAN, J. (org.). Caminhos da saúde pública no Brasil. Rio de Janeiro: Fiocruz, 2002.

IAMAMOTO, M. V. O serviço social na contemporaneidade: trabalho e formação profissional. 3. ed. São Paulo: Cortez, 2000. 
IAMAMOTO, M. V.; CARVALHO, R. Relações sociais e serviço social no brasil: esboço de uma interpretação históricometodológica. 7. ed. São Paulo: Cortez; Lima, Peru: Celats, 1982.

MARSHALL, T. H. Cidadania, classe social e status. Rio de Janeiro: Zahar, 1967.

MÉSZÁROS, I. A crise estrutural do capital. Outubro Revista, n. 2, 2000.

MINAYO, M. C. S. Pesquisa social: teoria, método e criatividade. 28. ed. Petrópolis: Vozes, 2009.

MOTA, A. E. Seguridade social brasileira: desenvolvimento histórico e tendências recentes. Serviço social e saúde: formação e trabalho profissional. São Paulo: Cortez, 2006.

NOGUEIRA, V. M. R.; MIOTO, R. C. T. Desafios Atuais do Sistema Único de Saúde - SUS e as Exigências para os Assistentes Sociais. In: MOTA, A. E et al. (org.). Serviço Social \& Saúde: formação e trabalho profissional. São Paulo: Cortez, 2006. https://doi.org/10.1590/s0034-89102006000100006

PAULO NETTO, J. Introdução ao estudo do método em Marx. São Paulo: Expressão Popular, 2011.

RAICHELIS, R. Democratizar a Gestão das Políticas Sociais: um desafio a ser enfrentado pela sociedade civil. Serviço Social e Saúde: formação e trabalho profissional. São Paulo: Cortez, 2006.

RAVAGNANI, C. L. C. A frente nacional contra a privatização da saúde: direito garantido, não se compra, não se vende. 2013. 247 f. Tese (Doutorado em Serviço Social) - Faculdade de Ciências Humanas e Sociais, Universidade Estadual Paulista - Júlio de Mesquita Filho|l, Franca, 2013. https://doi.org/10.17533/udea.rccp.v28n4a08

OMS. Organização Mundial da Saúde. Constituição da Organização Mundial de Saúde. Brasília: OMS, Brasil, 1946. https:// doi.org/10.7476/9788575413982

SARRETA, F. O. Educação permanente em saúde para os trabalhadores do SUS, v. 1. São Paulo: Cultura Acadêmica da Fundação UNESP, 2010. https://doi.org/10.7476/9788579830099

SIMÕES, C. Curso de direito do serviço social. 2. ed. São Paulo: Cortez, 2008. (Biblioteca Básica de Serviço Social, v. 3).

SOARES, L. T. Os custos sociais do ajuste neoliberal na América Latina. São Paulo: Cortez, 2000. (Coleção Questões da Nossa Época, v. 78).

Recebido em: 21/8/2018.

Aprovado em: 12/4/2019.

Publicado em: 10/10/2019.

Endereço para correspondência:

Fernanda de Oliveira Sarreta

Universidade Estadual Paulista

Av. Eufrásia Monteiro Petráglia, 900 - Prolongamento Jardim Dr. Antonio Petraglia

14409-160, Franca, SP, Brasil

\section{Autoras:}

Gabriela Cristina Braga Bisco

Doutoranda em Serviço Social. Programa de Pós-Graduação em Serviço Social da Universidade Estadual

Paulista (PPGSS/UNESP), Franca, São Paulo, SP, Brasil. A pesquisadora contou com bolsa da Coordenação de

Aperfeiçoamento de Pessoal de Nível Superior (CAPES) - Demanda Social para desenvolvimento da pesquisa.

Orcid: https://orcid.org/0000-0003-2820-7735

E-mail: gabrielacristina.bragabisco@gmail.com

FERNANDA DE OLIVEIRA SARRETA

Doutora em Serviço Social pela Universidade Estadual Paulista, UNESP. Docente do Curso de Graduação em

Serviço Social e coordenadora do Programa de Pós-Graduação em Serviço Social da Universidade Estadual

Paulista (PPGSS/UNESP), Franca, São Paulo, SP, Brasil.

Orcid: https://orcid.org/0000-0001-8001-3060

E-mail: fersarreta2009@yahoo.com.br 